\title{
High Expression of CCR7 Predicts Lymph Node Metastasis and Good Prognosis in Triple Negative Breast Cancer
}

\author{
Xuelu Lia,b Siwen Sun ${ }^{\mathrm{a}}$ Ning $\mathrm{Li}^{\mathrm{b}}$ Jiyue Gao Jing Yua Jinbo Zhao ${ }^{\mathrm{a}}$ Man $\mathrm{Li}^{\mathrm{a}}$ \\ Zuowei Zhao \\ aDepartment of Oncology \& Department of Breast Surgery, The Second Hospital of Dalian Medical \\ University, Dalian, 'Department of Foreign Language, Dalian Medical University, Dalian, China
}

\section{Key Words}

CCR7 • Breast cancer • Lymph node metastasis $•$ Prognosis

\begin{abstract}
Background/Aims: Previous preclinical and clinical studies have reported a positive correlation between the expression of the $\mathrm{C}-\mathrm{C}$ chemokine receptor 7 (CCR7) and the incidence of lymph node metastasis in breast cancer. However, the prognostic relevance of CCR7 expression in breast cancer remains contradictory till now. The aim of this study is to assess the correlation of the CCR7 expression with other clinicopathological features and prognosis in breast cancer. Methods: The CCR7 gene amplification and mRNA expression levels from approximately 3,000 patients were retrieved from human breast cancer databases and analyzed. Furthermore, a total of 188 primary triple negative breast cancer patients were enrolled in this study (diagnosed since January 2009 to January 2013 from the Second Hospital of Dalian Medical University). The protein levels of CCR7 were examined by immunohistochemistry using paraffin-embedded tumor tissues. Results: The analysis of gene amplification and mRNA levels showed the expression of CCR7 in breast cancer correlated with better prognosis. When we compared the CCR7 expressions in different subtypes, the basal-like group showed the highest expression of CCR7 and exhibited a better prognosis. Consistently, Kaplan-Meier analysis of 188 triple negative breast cancer patients showed that the prognosis of patients with positive CCR7 expression was significantly better than those with negative expression $(H R=0.642, p=0.0275)$. Additionally, we also observed a positive correlation between lymph node metastasis and the CCR7 expression $(p=0.0096)$. Conclusions: Our results indicated that elevated CCR7 expression as a marker for increased lymph node metastasis, in addition to serve as an independent prognostic indicator for better overall survival in triple negative breast cancer patients.
\end{abstract}




\section{Cellular Physiology Cell Physiol Biochem 2017;43:531-539 \begin{tabular}{l|l} 
and Biochemistry Publisher.1159/000480526 & $\begin{array}{l}\text { (c) } 2017 \text { The Author(s). Published by S. Karger AG, Basel } \\
\text { www.karger.com/cpb }\end{array}$
\end{tabular}}

Li et al.: CCR7 is an Independent Prognostic Indicator

\section{Introduction}

Transcriptional profiling analyses have identified the five subtypes of breast cancer, including normal-like, luminal A, luminal B, HER2-positive, and basal-like breast cancer [1]. Among these subtypes, basal-like breast cancer is strongly associated with aggressive phenotypes and poor prognosis [2]. This subtype largely overlaps with the clinically defined 'triple-negative' breast cancer, which lacks ER, PR, and HER2 expressions. The absence of these molecules renders this subtype unsusceptible to routine targeted therapies such as Herceptin/Trastuzumab. Therefore, to gain more understanding on this subtype, we set out to investigate the expressions of other molecules of prognostic significance.

Several preclinical and clinical studies [3-8] have reported positive correlations between the incidence of lymph node metastases and the expression levels of the $\mathrm{C}$ - $\mathrm{C}$ chemokine receptor 7 in breast cancer (Table 1). C-C chemokine receptor 7 (CCR7), a G proteincoupled trans-membrane protein, can promote immune cell viability and induce immune cells homing to secondary lymphoid organs following cognate ligand binding like cytokines CCL19 and CCL21 $[9,10]$. Whereas the exact roles of CCR7 in disease progression and in tumor metastasis to lymphoid tissues remain controversial so far.

Two clinical studies have been conducted to investigate the relationship between clinicopathological characteristics and the expression levels of CCR7, although the prognostic significance of CCR7 expression in breast cancer still remains contradictory (Table 1). The study by Liu et al [7]. reported that the CCR7 expression was correlated with lymph node metastases and a poor overall survival in breast cancers $(p=0.044)$. However, another study by Cassier et al [8]. did not draw the same conclusion, which reported that the expression of CCR7 was not significantly associated with either RFS ( $p=0.34)$ or OS $(p=0.153)$. In addition, we observed that an intriguing subset of breast cancer patients with lymph node metastases exhibited a relative long-term survival from our clinical work, which prompted us to investigate the correlation between lymph node metastasis and overall survival. In order to assess the correlations between the CCR7 expression and the clinicopathological features and overall survival, we analyzed the expressions of CCR7 using gene amplification and mRNA expression data from the breast cancer databases and examined the prognostic value of CCR7 expression. Subsequently, we inspected the expressions of CCR7 protein using immunohistochemistry in 188 triple negative breast cancer tissues. In this study, by combining the analyses of CCR7 expressions at the gene, mRNA, and protein levels, we endeavor to validate the correlations between the CCR7 expression and lymph node metastasis and the overall survival in triple negative breast cancers.

\section{Materials and Methods}

\section{Samples and Clinicopathological Data}

A total of 188 surgically resected breast cancer specimens and twelve normal breast tissues were collected from the Second Hospital of Dalian Medical University between January 2009 and January 2013. None of the patients had received radiotherapy or chemotherapy prior to surgery. The inclusion criteria for this study was as follows: 1) pathological examination as ER-, PR-, and HER2-, 2) more than 15 lymph nodes were examined after surgery, 3 ) the tumor specimens were unbroken and dyed uniformly by the antibody, and 4) the availability of a complete medical record. The demographic and clinical data of each patient were obtained from the medical records. Telephone follow-ups were performed every 3 months since the date of surgery. Written informed consent was obtained from all participants included in this study and the experimental protocol was approved by the ethics committee at the Second Hospital of Dalian Medical University. This study did not contain any studies with human participants or animals performed by any of the authors.

\section{Immunohistochemistry}

The tumor tissue samples were fixed in 10\% formalin (pH 7.0) before embedded in paraffin. The protein expression of CCR7 was measured following a two-step method. Rabbit anti-CCR7 polyclonal 
Table 1. Summary of correlation effects of CCR7 expression in breast cancer. OS, overall survival. LN metastases, lymph node metastases. "-", no reported

\begin{tabular}{|c|c|c|c|c|c|}
\hline Year & $\begin{array}{c}\text { NO. of } \\
\text { patients }\end{array}$ & $\begin{array}{l}\text { End } \\
\text { Point }\end{array}$ & $\begin{array}{c}\text { CCR7 } \\
\text { Positive vs. Negative }\end{array}$ & Correlation effects & Reference \\
\hline 2005 & 197 & os & - & $\begin{array}{l}\text { LN metastases } \\
(p=0.013)\end{array}$ & $\begin{array}{c}\text { Cabioglu } \mathrm{N} \text {, et al } \\
{[3]}\end{array}$ \\
\hline 2006 & 142 & os & - & $\begin{array}{l}\text { LN metastases } \\
\qquad(p=0.017)\end{array}$ & Andre F, et al. [4] \\
\hline 2007 & 44 & os & No significant $(\mathrm{p}=0.24)$ & - & $\begin{array}{c}\text { Cabioglu N, et al } \\
{[5]}\end{array}$ \\
\hline 2009 & 41 & OS & No significant $(p=0.24)$ & $\begin{array}{l}\text { Bone metastases } \\
\qquad(p=0.037)\end{array}$ & $\begin{array}{c}\text { Cabioglu N, et al. } \\
{[6]}\end{array}$ \\
\hline 2010 & 200 & os & $\begin{array}{l}\text { A shorter survival } \\
\qquad(p=0.044)\end{array}$ & $\begin{array}{l}\text { LN metastases } \\
(p<0.001)\end{array}$ & Liu Y, et al. [7] \\
\hline 2011 & 207 & RFS, OS & $\begin{array}{c}\text { No significant }(p=0.34 \\
p=0.153)\end{array}$ & - & $\begin{array}{c}\text { Cassier PA, et al. } \\
{[8]}\end{array}$ \\
\hline
\end{tabular}

antibody (1:100) was purchased from Bioss (bs-1305R, China). The DAB kit was purchased from Zhongshan Goldenbridge Biotechnology Company (Beijing, China). All procedures were carried out according to the manufacturer's instructions.

\section{Assessment of immunohistochemistry staining}

CCR7 positive staining was defined as samples displaying clear brown granules in the cytoplasm. The staining was assessed by two experienced pathologists independently, who were blinded to diagnosis and prognosis. The expression levels were evaluated by the proportion and intensity of positively stained cells. The staining intensity was as follows: 0 , negative; 1 , light yellow; 2 , brownish-yellow; 3 , brown. The proportion score was as follows: 0 , none; $1,<25 \% ; 2,25 \%-50 \% ; 3,>50 \%$. Total score $<3$ was treated as negative and a score $\geq 3$ was considered as positive.

\section{Statistical analysis}

Statistical analyses were performed using Prism 6. In the dot plots, each dot indicated an individual sample, with results representing median with interquartile ranges. Data of the cohorts were downloaded from cBioPortal (www.cbioportal.com). Two-tailed Student's t-test and analysis of variance (ANOVA) were carried out to compare between two groups and among three groups, respectively. Kaplan-Meier curve, logrank (Mantel-Cox) test, and the hazard ratio were analyzed using Prism 6 and the online analytical system (http://kmplot.com/analysis/index, http://xena.ucsc.edu/public-hubs/). P-value $<0.05$ was considered statistically significant.

\section{Results}

The recurrent CCR7 gene amplification predicts a better prognosis

We analyzed the amplification of CCR7 gene in four breast cancer cohorts retrieved from the cBioPortal, including TCGA_2015, TCGA, TCGA_pub, and METABRIC. We observed that the amplification of $C C R 7$ gene was recurrent, at approximately 4-6\% (Fig. 1A). We next assessed the prognostic significance of $C C R 7$ amplification in the TCGA_Pub breast cancer cohort, with results suggesting that cases with amplifications showed a better prognosis than those without amplification ( $\mathrm{p}=0.0435$ ) (Fig. 1B). To assess whether CCR7 mRNA expression levels can also predict prognosis, patients were divided into top $50 \%$ ' $C C R 7 \mathrm{high}$ ' and bottom $50 \%$ 'CCR7 low' groups based on the CCR7 mRNA levels and Kaplan-Meier curves of overall survival were plotted. The survival analysis showed a consistent conclusion that the high CCR7 expression survived longer with high expression of CCR7 till approximately 210 weeks ( $p=0.0207, p=0.0002531$ ) (Fig. 1C). Our findings indicate that the CCR7 overexpression at both gene and mRNA levels can predict a good prognosis in breast cancers.

\section{CCR7 is overexpressed in triple negative breast cancer}

We next analyzed the gene expression data across three independent cohorts with a total number of about 3, 000 patients, including TCGA 2012_nature, TCGA_provisional, and 
Fig. 1. CCR7 gene amplification predicts a better prognosis. (A, B) The data is analyzed by www.cbioportal.org. Samples were divided into two groups with and without CCR7 gene amplifications. Kaplan-Meier curves of overall survival of breast cancer patients were analyzed by using Prism 6 (left), and the online analytical system (right) from http://xena.ucsc.edu/ public-hubs/.Samples were divided into two groups with high and low expression levels of CCR7.

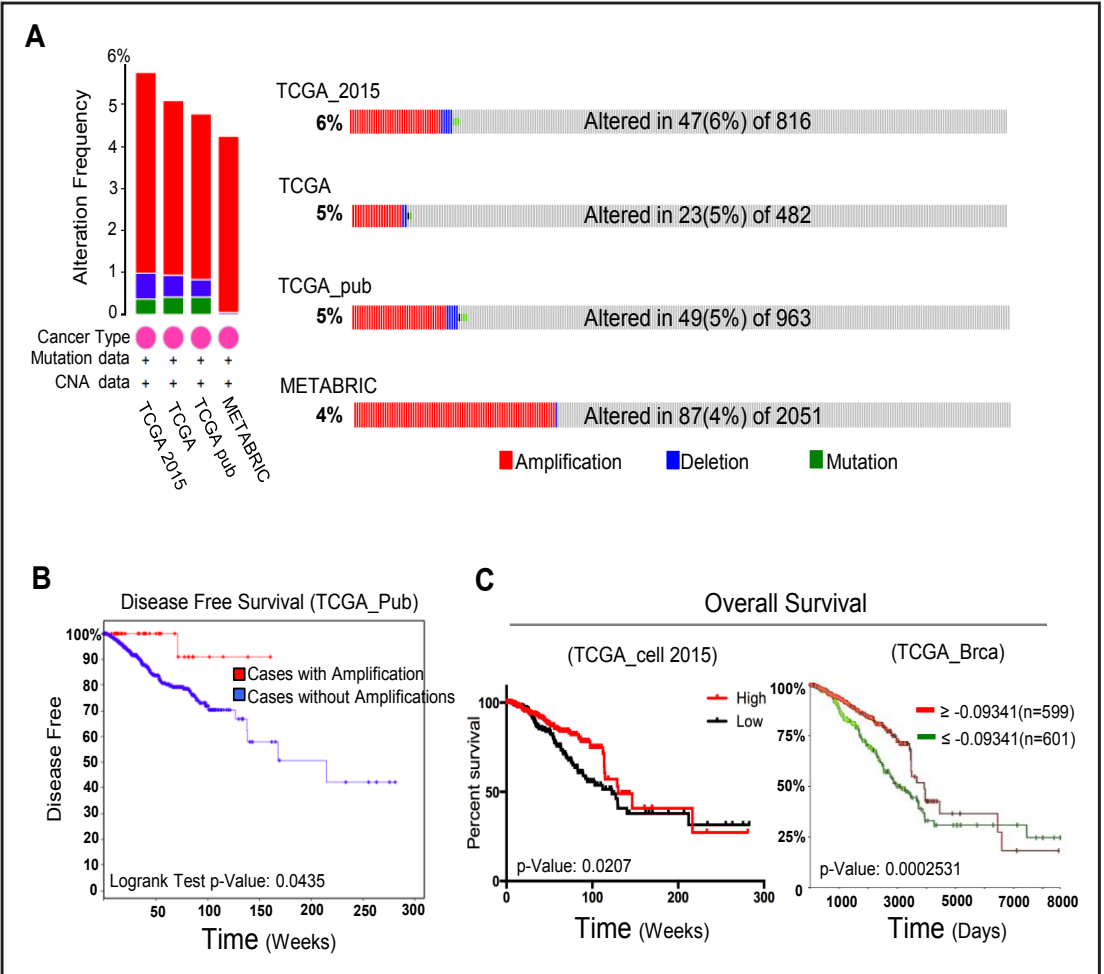

Brca_metabric. With respect to the various subtypes of breast cancer, we observed that the ER-positive subtype displayed low expression levels of CCR7, while the HER2-positive and basal-like subtypes showed relative high expression levels of $C C R 7$, even more obviously in the basal-like subtype (Fig. 2A). These results indicate that CCR7 expression is elevated in breast cancers lacking the expression of ER, while the basal-like group showed the highest expression levels of $C C R 7$ among breast cancer subtypes.

High expression levels of CCR7 predict good prognosis in triple negative breast cancer

To assess the prognostic significance of $C C R 7$ expression in breast cancer, patients were divided into high expression and low expression groups based on the expression of CCR7 in HER2-positive breast cancer and basal-like breast cancer. By analyzing survival data, we draw similar conclusions from both subtypes that 'CCR7 high' group showed a better prognosis ( $p=0.0058, p=0.0199$ ) (Fig. 2B). Besides, using another web-based analysis tool (http://kmplot.com), we reached the same conclusion that 'CCR7 high' group had a significantly better prognosis in the basal-like subtype of breast cancer ( $\mathrm{p}=0.029)$ (Fig. 2C). Taken together, the results from our analyses show that the high expression of CCR7 was correlated with good prognosis in HER2 positive and basal-like breast cancers, with more significant association observed in the basal-like subtype.

\section{Clinical relevance of CCR7 protein expression}

Subsequently, we investigated whether the protein expression of CCR7 was associated with clinicopathological features in triple negative breast cancer. Therefore, we measured the CCR7 protein expressions in breast cancer tissues with immunohistochemistry (Fig. 3), from which we observed CCR7 staining of the cytoplasm and nuclear membrane that was further confirmed by carrying out immunofluorescence experiments (Fig. 3). Based on results from immunohistochemical analyses, no significant statistical association of CCR7 expression was observed with patient age, number of metastatic axillary nodes, and histologic grade (Table 2). However, the expression of CCR7 was significantly associated with the diameter of primary tumor $(\mathrm{p}=0.0409)$ and TNM staging $(\mathrm{p}=0.0001)$. 


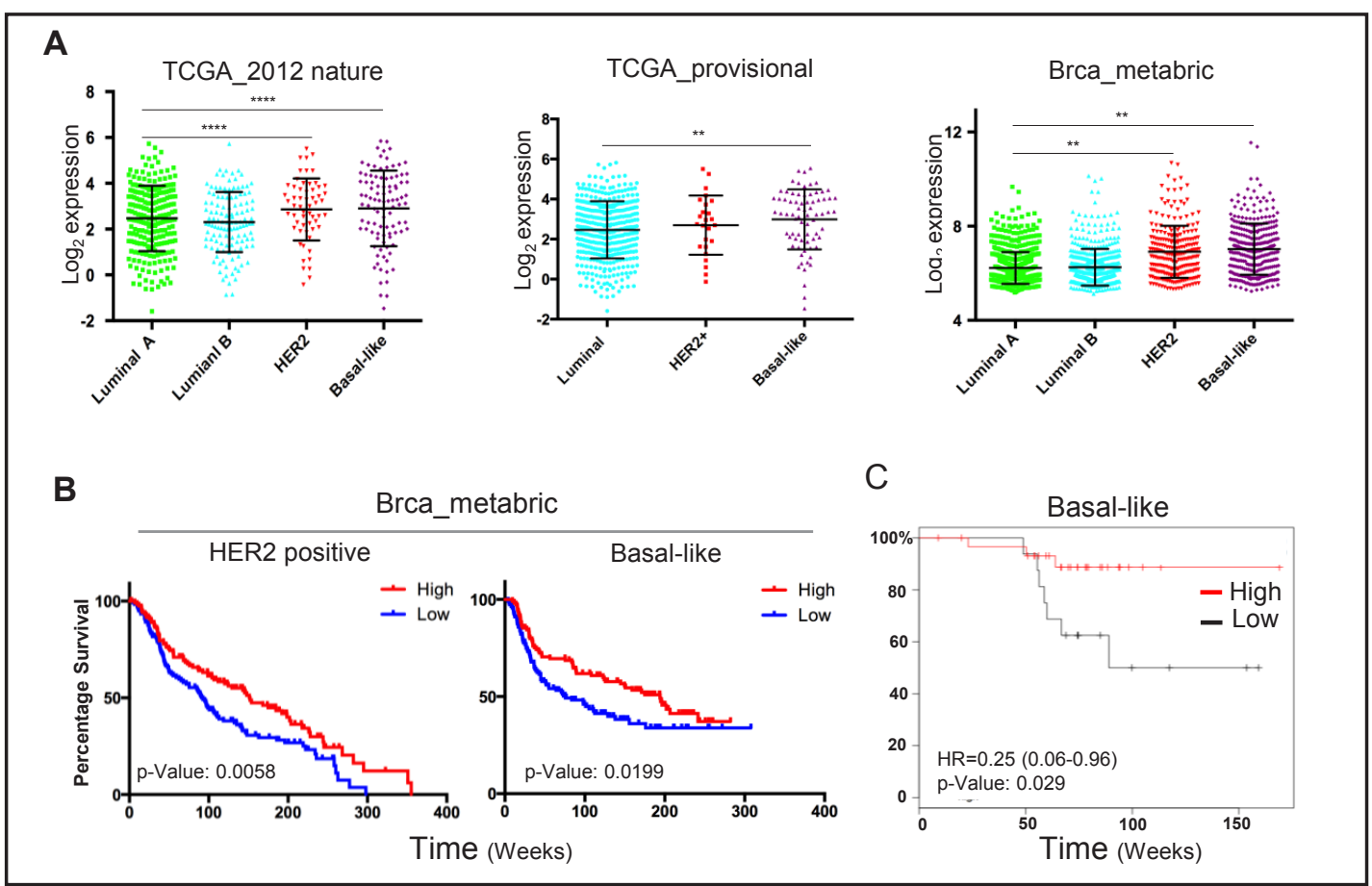

Fig. 2. CCR7 is overexpressed in basal-like breast cancer and its overexpression predicts good prognosis. (A) The CCR7 expression among four subtypes of breast cancer. Black lines in each group indicate median with interquartile range. (B) Kaplan-Meier curves of the Brca_metabric cohort were analyzed by Prism 6. Samples were divided into top 50\% 'CCR7 high' and bottom 50\% 'CCR7 low' groups based on the expression of CCR7 in HER2-positive breast cancer, meanwhile patients also were divided into top 35\% 'CCR7 high' and bottom 35\% 'CCR7 low' groups in basal-like breast cancer. (C) Kaplan-Meier curve was analyzed by http:// kmplot.com. Samples were divided into two groups as (B) left panel. ${ }^{* *} \mathrm{p}<0.01,{ }^{* * * *} \mathrm{p}<0.0001$ (Student's t test).

Fig. 3. Evaluation of immunohistochemical staining for CCR7. Notes: (A) and (B) represented negative immunohistochemical staining for normal breast tissue and breast cancer. Immunostaining scores of cancer tissues indicating $0+, 1+, 2+, 3+$, respectively in (C), (D), (E), (F). Scar

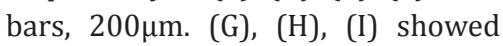
representative images of immunofluorescence, anti-CCR7 (green) and DAPI (blue).

In this study, a total of 188 cases were followed up for 46 months after surgery. The median survival time was 32 months. Ninety-seven patients died during follow-up, and all causes of death were cancer related. We performed Coxregression analysis to evaluate

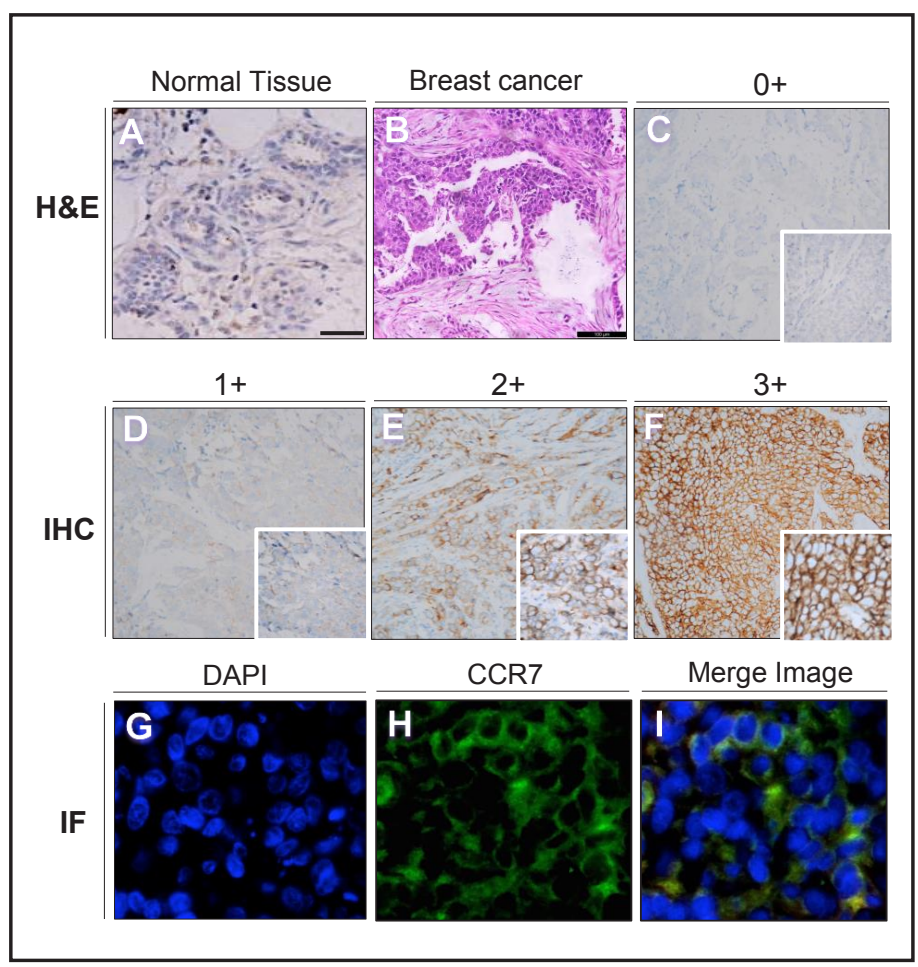




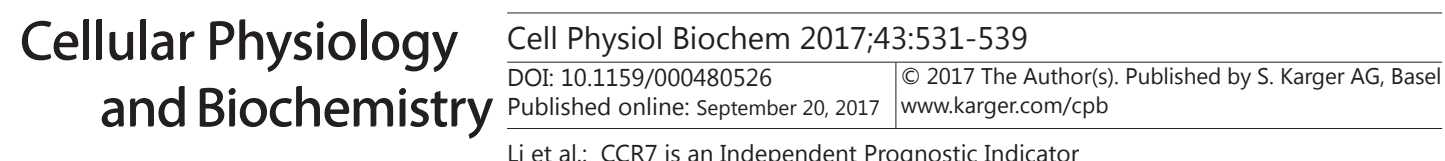

clinical factors, which showed that TNM staging $(\mathrm{P}=0.0137, \mathrm{HR}=0.6142)$ and CCR7 expression levels $(p=0.0275, H R=0.6330)$ were significantly correlated with overall survival (Table 3 and Fig. 4).

The overexpression of CCR7 predicts lymph node metastases in triple negative breast cancers

In previous studies [3-8], the CCR7 expression was shown to be positively correlated with the incidence of lymph node metastases, while its predictive value of prognosis in breast cancer remains contradictory (Table 1). Having investigated the prognostic relevance of the expression of CCR7, we then turned to assess whether CCR7 expression was associated with the incidence of lymph node metastases. The expression levels of CCR7 showed a positive correlation with the incidence of lymph node metastases ( $p=0.0096)$, suggesting that CCR7 positive samples likely had a higher rate of lymph node metastases (Fig. 4A). These results indicated that triple negative breast cancers overexpressing CCR7 exhibited a better prognosis but showed a higher rate of lymph node metastases. The reason, why triple negative breast cancers expressed CCR7 at high levels and resulted in a better overall prognosis, would be explained in the discussion section.
Table 2. The correlation between CCR7 expression and clinicopathological features

\begin{tabular}{|c|c|c|c|c|}
\hline \multirow{2}{*}{ Variable } & \multirow{2}{*}{ Patients } & \multicolumn{2}{|c|}{ CCR7 } & \multirow{2}{*}{$\begin{array}{c}\mathrm{P} \\
\text { Value }\end{array}$} \\
\hline & & Low & High & \\
\hline \multicolumn{5}{|c|}{ Age(year)- no. (\%) } \\
\hline$\leq 50$ & $94(50 \%)$ & 50 & 44 & \multirow{2}{*}{0.8837} \\
\hline$>50$ & $94(50 \%)$ & 52 & 42 & \\
\hline \multicolumn{5}{|c|}{ No. of metastatic axillary nodes - no. (\%) } \\
\hline 0 & $42(22 \%)$ & 25 & 17 & \multirow{3}{*}{0.1237} \\
\hline $1-3$ & $90(48 \%)$ & 53 & 37 & \\
\hline$>3$ & $56(30 \%)$ & 24 & 32 & \\
\hline \multicolumn{5}{|c|}{ Diameter of primary tumor - no. $(\%)$} \\
\hline$\leq 30 \mathrm{~mm}$ & $90(48 \%)$ & 56 & 34 & \multirow{2}{*}{0.0409} \\
\hline$>30 \mathrm{~mm}$ & $98(52 \%)$ & 46 & 52 & \\
\hline \multicolumn{5}{|c|}{ Histologic grade - no. $(\%)$} \\
\hline 1 & $29(15 \%)$ & 13 & 16 & \multirow{3}{*}{0.4260} \\
\hline 2 & $116(62 \%)$ & 63 & 53 & \\
\hline 3 & $43(23 \%)$ & 26 & 17 & \\
\hline \multicolumn{5}{|c|}{ TNM staging } \\
\hline I & $36(19 \%)$ & 2 & 34 & \multirow{4}{*}{0.0001} \\
\hline II & $78(41 \%)$ & 40 & 38 & \\
\hline III & $50(27 \%)$ & 48 & 17 & \\
\hline IV & $25(13 \%)$ & 13 & 12 & \\
\hline
\end{tabular}

Table 3. Cox regression analysis of overall survival

\begin{tabular}{lccccc}
\hline End Point & no. of patients & Hazard ratio $(95 \%$ CI) & P-value \\
\hline Age $(\leq 50$ years VS $>50$ years) & 93 & 95 & $0.6978(0.464-1.049)$ & 0.0833 \\
CCR7 expression (Low VS High) & 102 & 86 & $0.6330(0.422-0.951)$ & 0.0275 \\
Metastatic axillary nodes $(<3$ VS $\geq 3$ ) & 106 & 82 & $1.1090(0.737-1.668)$ & 0.6197 \\
Diameter of primary tumor $(\leq 30 \mathrm{~mm}$ VS $>30 \mathrm{~mm})$ & 104 & 84 & $1.0860(0.723-1.632)$ & 0.6917 \\
Histologic grade (1/2 VS 3) & 145 & 43 & $0.9662(0.606-1.540)$ & 0.8850 \\
TNM staging (I/II VS III/IV & 114 & 74 & $0.6142(0.385-0.888)$ & 0.0137 \\
\hline
\end{tabular}

Fig. 4. The expression of CCR7 predicts lymph node metastasis and good prognosis in triple negative breast cancer. Each dot indicated the number of lymph node metastases for an in-
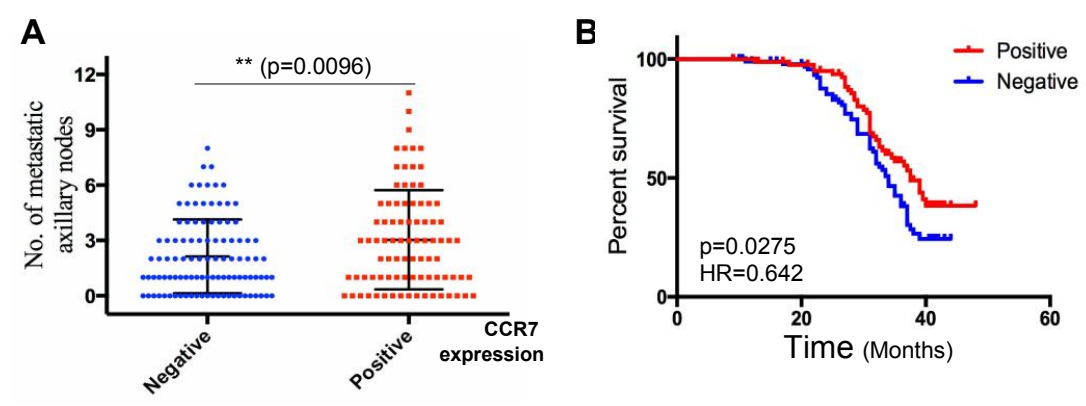
dividual sample.

Samples were classified into CCR7 negative and CCR7 positive groups. Black lines in each group indicated median with interquartile range. (B) Kaplan-Meier analysis of overall survival of triple negative breast cancer patients. Samples were divided into two groups as (A). ${ }^{* *} \mathrm{p}<0.01$. 


\section{Cellular Physiology Cell Physiol Biochem 2017;43:531-539 \begin{tabular}{ll|l} 
and Biochemistry Published onlIne: September 20, 2017 & $\begin{array}{l}\text { (c) } 2017 \text { The Author(s). Published by S. Karger AG, Basel } \\
\text { www.karger.com/cpb }\end{array}$ \\
\hline
\end{tabular} \\ Li et al.: CCR7 is an Independent Prognostic Indicator}

\section{Discussion}

In the present study, we investigated the expression of CCR7 in various breast cancer subtypes using data from the gene, mRNA, and protein levels. To the best of our knowledge, the current study provides one of the most comprehensive reports on CCR7 expressions in breast cancer in the literature. From the combined results of these analyses, we can draw a unanimous conclusion that CCR7 can serve as a potential prognostic marker, with best predictive value in the triple negative breast cancer subtype.

To address the relationship between CCR7 expression and patient prognosis, we first analyzed CCR7 gene amplification in breast cancer database and found a prognostic correlation. Further analysis with mRNA expression data confirmed such result, which led to a consistent conclusion that the high expression levels of CCR7 mRNA also predict a good prognosis, especially in the basal-like subtype. Importantly, we verified the prognostic significance of CCR7 expression using the results from the immunohistochemical analysis of 188 triple negative breast cancer tissues. Consistent with our observations with data from the gene and mRNA levels, the CCR7 protein positive group also showed a better prognosis. Previous studies $[3,4,7]$ have reported a higher rate of lymph node metastases in the CCR7 positive group, and similar results were also reached in this present study (Table 1).

The functions of CCR7 involve the regulation of the migration of immune cells to lymph nodes $[11,12]$. Such roles have been extensively studied in adaptive immunity and secondary lymphoid organogenesis [13, 14]. The CCR7-null mice mutant displayed a disrupted architecture of the thymus and lymph nodes, as well as reduced primary immune response [9]. Hence, we hypothesize that the expression of CCR7 could increase the migration of breast cancer cells to lymph nodes. However, it remains obscure how the increased migration of breast cancer cells to lymph nodes led to good prognosis. We have considered several possibilities, which are as follows. Firstly, it was unclear what functions CCR7 positive cancer cells in lymph nodes played during the development and progression of cancer. CCR7 positive cancer cells actively directed metastasis to lymph nodes but might also activate the immune system to trap escaped tumor cells [15]. In support of this notion, previous studies have reported that CCR7 actively targeted migration to the lymph nodes, but led to less efficient metastasis to the lung in PyVmT mice models [9]. The correlation between chemokine receptors and lymph node metastases could provide a new understanding of breast cancer metastasis, which is worthy for further studies to develop novel therapies. Secondly, an appropriate mice model is required to understand the development of targeting metastasis from the mammary fat pad to the lymph nodes. Boyle et al [16]. reported that CCR7 was not implicated in enhancing breast tumor growth or regulating breast tumor proliferation in a tissue-specific manner. The CCR7 positive tumors might be more sensitive to chemotherapy, leading to a longer survival time in CCR7 positive patients. However, no such study was carried out yet in this regard, thus in our further studies we will try to address this issue in order to reveal the implications of CCR7 expression. Interestingly, Gracio et al [17]. identified that the CCR7 splicing imbalance was associated with clinical outcomes. Therefore, a close examination of CCR7 alternative splicing in breast cancer should be performed to disclose the associations of this key post-transcriptional regulation with patient survival [18].

The major limitation of the current study is due to the retrospective analysis. Meanwhile, the small sample size reduced the statistical power, and the limited number of samples expressing CCR7 should also be considered as a limiting factor in data analysis. In addition, the data presented here did not fully address the reason why triple negative breast cancers expressed CCR7 at high levels and resulted in a better overall prognosis. Further studies using cancer cell lines and animal models will be explored to gain more mechanistic insights into the implications of CCR7 expression in disease progression. 


\section{Cellular Physiology Cell Physiol Biochem 2017;43:531-539 \begin{tabular}{ll|l} 
and Biochemistry Published onlIne: September 20, 2017 & $\begin{array}{l}\text { C } 2017 \text { The Author(s). Published by S. Karger AG, Basel } \\
\text { www.karger.com/cpb }\end{array}$ \\
\hline
\end{tabular}}

Li et al.: CCR7 is an Independent Prognostic Indicator

\section{Acknowledgements}

We thank all patients enrolled in this study. This work was supported by the National Natural Science Foundation of China (No.81071127, NO.81471751 and N0.81673762 to Zuowei Zhao; No.81650018 to Man Li), and Provincial Natural Science Foundation of Liaoning (NO.2014921059 to Zuowei Zhao; No.2014023025 to Man Li).

\section{Disclosure Statement}

The authors declare no Disclosure Statement.

\section{References}

1 Dietze EC, Sistrunk C, Miranda Carboni G, O Regan R, Seewaldt VL: Triple-negative breast cancer in AfricanAmerican women: disparities versus biology. Nat Rev Cancer 2015;15:248-254.

-2 David R, Alfred VH, Peter R, Agnes BN: Zinc distribution within breast cancer tissue: A possible marker for histological grading? J Cancer Res Clin Oncol 2015;141:1321.

-3 Cabioglu N, Yazici MS, Arun B, Broglio KR, Hortobagyi GN, Price JE, Sahin A: CCR7 and CXCR4 as Novel Biomarkers Predicting Axillary Lymph Node Metastasis in T1 Breast Cancer. Clin Cancer Res 2015;11:5686-5693.

-4 Andre F, Cabioglu N, Assi H, Sabourin JC, Delaloge S, Sahin A, Broglio K, Spano JP, Combadiere C, Bucana C, Soria JC, Cristofanilli M: Expression of chemokine receptors predicts the site of metastatic relapse in patients with axillary node positive primary breast cancer. Ann Oncol 2006;17:945-951.

-5 Cabioglu N, Gong Y, Islam R, Broglio KR, Sneige N, Sahin A, Gonzalez-Angulo AM, Morandi P, Bucana C, Hortobagyi GN, Cristofanilli M: Expression of growth factor and chemokine receptors: new insights in the biology of inflammatory breast cancer. Ann Oncol 2007;18:1021-1029.

6 Cabioglu N, Sahin AA, Morandi P, Meric-Bernstam F, Islam R, Lin HY, Bucana CD, Gonzalez-Angulo AM, Hortobagyi GN, Cristofanilli M: Chemokine receptors in advanced breast cancer: differential expression in metastatic disease sites with diagnostic and therapeutic implications. Ann Oncol 2009;20:1013-1019.

7 Liu Y, Ji R, Li J, Gu Q, Zhao X, Sun T, Wang J, Li J, Du Q, Sun B: Correlation effect of EGFR and CXCR4 and CCR7 chemokine receptors in predicting breast cancer metastasis and prognosis. J Exp Clin Cancer Res 2010;29:16.

-8 Cassier PA, Treilleux I, Bachelot T, Ray-Coquard I, Bendriss-Vermare N, Ménétrier-Caux C, Trédan O, Goddard-Léon S, Pin JJ, Mignotte H, Bathélémy-Dubois C, Caux C, Lebecque S, Blay JY: Prognostic value of the expression of C-Chemokine Receptor 6 and 7 and their ligands in non-metastatic breast cancer. BMC Cancer 2011;11:213.

-9 Stacer AC, Fenner J, Cavnar SP, Xiao A, Zhao S, Chang SL, Salomonnson A, Luker KE, Luker GD: Endothelial CXCR7 regulates breast cancer metastasis. Oncogene 2016;35:1716-1724.

-10 Dong Z, Chen Y, Peng Y, Wang F, Yang Z, Huang G, Chen Y, Yuan Z, Cao T, Peng Y: Concurrent CCR7 Overexpression and RelB Knockdown in Immature Dendritic Cells Induces Immune Tolerance and Improves Skin-Graft Survival in a Murine Model. Cell Physiol Biochem 2017;42:455-468.

$>11$ Tutunea-Fatan E, Majumder M, Xin X, Lala PK: The role of CCL21/CCR7 chemokine axis in breast cancerinduced lymphangiogenesis. Mol Cancer 2015;14:35.

12 Yang N, Zhou TC, Lei XX, Wang C, Yan M, Wang ZF, Liu W, Wang J, Ming KH, Wang BC, Xu BL, Liu Q: Inhibition of Sonic Hedgehog Signaling Pathway by Thiazole Antibiotic Thiostrepton Attenuates the CD44+/CD24Stem-Like Population and Sphere-Forming Capacity in Triple-Negative Breast Cancer. Cell Physiol Biochem 2016;38:1157-1170.

13 El-Ghonaimy EA, El-Shinawi M, Ibrahim SA, El-Ghazaly H, Abd-El-Tawab R, Nouh MA, El-Mamlouk T, Mohamed MM: Positive lymph-node breast cancer patients-activation of NF-KB in tumor-associated leukocytes stimulates cytokine secretion that promotes metastasis via C-C chemokine receptor CCR7 FEBS J 2014;282:271-282. 


\section{Cellular Physiology Cell Physiol Biochem 2017;43:531-539 \begin{tabular}{ll|l} 
DOI: 10.1159/000480526 & $\begin{array}{l}\text { O 2017 The Author(s). Published by S. Karger AG, Basel } \\
\text { www.karger.com/cpb }\end{array}$ \\
\cline { 2 - 3 }
\end{tabular} \\ Li et al.: CCR7 is an Independent Prognostic Indicator}

14 Zhu A, Li Y, Song W, Xu Y, Yang F, Zhang W, Yin Y, Guan X: Antiproliferative Effect of Androgen Receptor Inhibition in Mesenchymal Stem-Like Triple-Negative Breast Cancer. Cell Physiol Biochem 2016;38:10031014.

15 Chuang CW, Pan MR, Hou MF, Hung WC: Cyclooxygenase-2 Up-Regulates CCR7 Expression Via AKTMediated Phosphorylation and Activation of Sp1 in Breast Cancer Cells. J Cell Physiol 2013;228:341-348.

16 Boyle ST, Ingman WV, Poltavets V, Faulkner JW, Whitfield RJ, McColl SR, Kochetkova M: The chemokine receptor CCR7 promotes mammary tumorigenesis through amplification of stem-like cells. Oncogene 2015;35:105-115.

-17 Gracio F, Burford B, Gazinska P, Mera A, Mohd Noor A, Marra P, Gillett C, Grigoriadis A, Pinder S, Tutt A, de Rinaldis E: Splicing imbalances in basallike breast cancer underpin perturbation of cell surface and oncogenic pathways and are associated with patients' survival. Sci Rep 2017;7:40177.

-18 Chen X, Wu J, Huang H, Ding Q, Liu X, Chen L, Zha X, Liang M, He J, Zhu Q, Wang S, Xia T: Comparative Profiling of Triple-Negative Breast Carcinomas Tissue Glycoproteome by Sequential Purification of Glycoproteins and Stable Isotope Labeling. Cell Physiol Biochem 2016;38:110-121. 